\title{
Review of the Effects of Friction Stir Welding Speed on Stainless Steel Type 304L
}

\author{
S. Sulaiman, S. Emamian, M. N. Sheikholeslam, and M. Mehrpouya
}

\begin{abstract}
Friction Stir Welding (FSW) is a solid state welding method and is common for aluminum alloys. There have been many studies to apply this process for high melting materials such as steels and titanium. To make it applicable, there are many variables that must be considered, which one of them is FSW speed. Welding on high melting materials such as steels and titanium with traditional methods needs too high energy, many welders, electrodes, and generally is time consuming. By using friction stir welding, cost would be reduced on consumable materials, welders and energy. However, considerations of feasibility and different conditions for optimizing the method are so important. In this review paper, the main discussion was about stainless steel 304L and investigated the effects of friction stir welding speeds. Finally, a brief discussion was presented to summarize the effects of speed on friction stir welding.
\end{abstract}

Index Terms-304L, friction stir welding, FSW, speed stainless steel.

\section{INTRODUCTION}

Stainless steels are engineering materials. Their corrosion resistance is high and this resistance arises from high amount of Chromium. In order to define the stainless steel, it can be said that the base alloy for this material is iron which contains a minimum of $\% 11$ Chromium (Cr) [1]. The stainless steels are divided into five categories: austenitic, ferritic, duplex, precipitation hardening and martensitic. The material that would be discussed in this review is stainless steel 304L which falls into the austenite category. According to The Welding Institute (TWI) the standard code of 304L from American Iron and Steel Institute (AISI) is commonly used in pressure vessels and weldability of this code examined by friction stir welding.

One of the non-fusion welding methods that was invented by The Welding Institute (TWI) in UK in 1991 is Friction Stir Welding (FSW) [2]. The application of this method is in Marine, Aerospace, Automotive, Rail and construction. This process was developed for $\mathrm{Al}, \mathrm{Mg}, \mathrm{Cu}, \mathrm{Zn}$ and demonstrated in Steels, Ti, Ni [3]. This invention is a big success for Aluminium alloys joints and low melting temperature materials. By this process there is no need for filler metals, better joint strengths, distortion and residual stresses are decreased. Fig. 1 shows the schematic of FSW.

Manuscript received December 25, 2012; revised February 10, 2013.

Shamsuddin Sulaiman and are with the Department of Mechanical and Manufacturing Engineering, Universiti Putra Malaysia.

Seyed Sattar Emamian and Mehrshad Mehrpouya are with the Department of Manufacturing Systems Engineering from Universiti Putra Malaysia (e-mail: sattr.emamian@gmail.com).

Mohammad Nassir Sheikholeslam is with the Department of Industrial Engineering from Umiversiti Putra Malaysia.

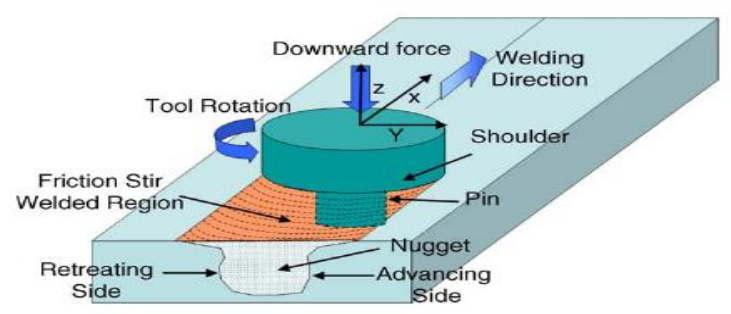

Fig. 1. Schematic drawing of friction stir welding [18].

It is notable that Friction Stir Welding has many uses for aluminium and also extensive research in this field has been done. Using this method to other metals, particularly stainless steels will help in production efficiency. Hence, in this review the main discussion is about stainless steel 304L to investigate the effects of friction stir welding speeds.

In FSW there are two important factors, tool rotating $(\omega$, zpm) and travel speed $(v, \mathrm{~mm} / \mathrm{min})$.It is very obvious that high and low speed would cause problems in joining the material. For instance, high speed would cause lack of penetration and also lack of material aggregation, On the other hand too hot processing conditions can cause flash formation or nugget collapse. While, under too cold condition insufficient flowing or lack of fill would occur on the advancing side [4].In general, because the heat generated would create by the friction between the tool and base metal, speed of the tool and finally welding speed is very important to consider. Many scholars did their researches on thermal issues and heat generation on the stainless steels that their results can be effective in this process.

According to findings in Reynolds et al. [5], residual stress of 304L stainless steel in FSW, are the same in character and magnitude with fusion welding. Furthermore, lower energy input due to lower tool rotation would conclude to lower weld temperature and a fine weld nugget grain size. Cho et al [6], examined FSW on 409 stainless steel that is kind of ferritic by Polycrystalline Cubic Boron Nitride (PCBN) tool, they found that fine grain microstructure was settled by dynamic recrystallization because of high heat generation and shear deformation. Jata, Semiatin. [7], Heitz and Skrotzki. [8] have proposed that stainless steels type 304 and 304L have lower stacking fault energy. Sato et al. [9] have examined recrystallization in type $304 \mathrm{~L}$ and found that the first is dynamic recrystallization during intense deformation that in conclusion disparate distribution of dislocation density is achieved within structure. Park et al. [10] found that stir zone and Thermo Mechanically Affected Zone (TMAZ) was dynamically recrystallized. T. Saeid et al [11] found that increase in welding speed decreases the recrystallized grain size. 


\section{LITERATURE REVIEW AND DISCUSSION}

FSW is a thermo-mechanical phenomenon, there is much material motion and shear force and also the temperature will increase to below the melting point [12], [13].Friction Stir Welding is a process that is strongly influenced by heat generation and heat flow [14]. Contact between tool and workpiece due to rotating tool and travel along the weld can make friction that is cause of heat generation in FSW. Tool of welding as mentioned before consists of pin and shoulder that the surface of shoulder can generate majority of heat [12].

Austenitic stainless steels have a good ductility, high strength, corrosion resistance, and also good weldability hence; it is popular in use and also has been the focus of researches [15]. It is important that the flow, ductility and work hardening of 304L are affected by the strain rate [15]. According to prior studies friction stir welding on stainless steels type 304 and $304 \mathrm{~L}$ have good recrystallized grain in stir zone [16]. During the welding friction between the tool and work piece and also plastic deformation are cause of heat generation [17].

High speed rotating tool causes more heat due to friction. The point that should be considered is that for high melting material like as stainless steels in this process preheating is one of the factors for making suitable plastic area [18].

Arbegast [19] represented an equation for maximum FSW process temperature that indicates the effects of rotational and welding speeds on the welding temperature.

$$
\frac{\mathrm{T}}{T_{m}}=k\left(\frac{\omega^{2}}{v \times 10^{4}}\right)^{\alpha}
$$

where $T$ is the FSW temperature $\left({ }^{\circ} \mathrm{C}\right), T_{m}$ is the melting temperature of the sheet material $\left({ }^{\circ} \mathrm{C}\right), \alpha$ and $\mathrm{k}$ are two defined constants and also $\omega$ and $v$ are the tool rotational and welding speeds respectively. Referred to (1), the FSW process temperature is related to the $\omega^{2} / v$ ratio. It means that increasing the rotational speed at a constant welding speed or decreasing the welding speed at a constant rotational speed leads to a higher welding temperature. It also indicates that the variations of tool rotational speed have higher effects on the process temperature than the welding speed variations [19] and [20].

On the other hand too hot processing conditions can cause flash formation or nugget collapse. While, under too cold condition insufficient flowing or lack of fill would occur on the advancing side [21].

Frictional heat calculated by $q_{f}=F_{f} V$

where, $F_{f}$ is local friction force that according to Coulomb's friction law can be calculated as $F_{f}=\mu F_{n}$

In above equations, $V$ is rotational velocity of the pin, which $V=2 \pi R N$ and $\mu$ is the friction coefficient between the tool and work piece, and $F_{n}$ is the normal force applied to the work piece. In velocity equation, $R$ is distance of calculated point from the tool axis and $\mathrm{N}$ is the rotational speed of the tool [22].

It is obvious that rotational and traveling speeds are main factors in heat generation and also heat input issues. The relation between speeds and heat input is complex during FSW. Too much or too low heat input affect the weld quality. If the heat input is too low, suitable plastic conditions prevented that causing voids during welding and in extreme cases the tool may break. On the other hand, with high heat input weld properties are excessively deteriorated. Generally, lower heat input in friction stir welding cause improve mechanical properties as well as decreased distortion and residual stress [24].

According to [23], [25], following equation describing the heat input during the FSW:

$$
Q=\frac{4}{3} \pi^{2} \frac{\eta \mu p \omega R^{3}}{v}
$$

where $Q$ is the heat input per unit per length, $\eta$ is the heat input efficiency, $R$ is the radius of the shoulder, and $\mu$ is the friction coefficient. Result to the equation by increasing the traveling speed $v$ and decreasing the rotation speed, heat input $Q$ would decreases. Also, peak temperature decreases by increasing welding speed at a constant tool rotation speed.

The other factor that can help for understanding the FSW and specially have a role in determining the speed of welding is strain rate, which is important to understand the material flow in stir zone. Thus, many researches have tried to find strain rate during FSW [21].According to prior studies friction stir welding on stainless steels type 304 and 304L have good recrystallized grain in stir zone [10], [16].

Welding variables can be named rotational speed of tool, vertical pressure on the tool, tilt angle of the tool, and design of the tool, which independent and also have main role in FSW process. The other variables that are depending on the above variables are: the rate of heat generation, cooling rate, force in $\mathrm{X}$ direction, and torque [17].

\section{CONCLuSion}

According to aforementioned studies, increase in welding speed will reduce the recrystallized grain size. Also, more heat will be caused by high speed rotating tool due to friction. It is notable that for high melting material like as stainless steels in FSW, to make a suitable plastic area, preheating is one of the key factors.

The main factors in heat generation and heat input issues are rotational and traveling speeds. The relation between speeds and heat input is complex during FSW. If the heat and temperature are too much or too low, heat input will affect the weld quality. If the heat input is too low, suitable plastic conditions will be prevented and will cause voids during welding and eventually, in extreme cases, the tool may break. Generally, lower heat input in friction stir welding cause improve mechanical properties as well as decreased distortion and residual stress. The other factor that can help to understand the FSW, which has a special role in determining the speed of welding, is strain rate, which is essential to understand the material flow in stir zone. Thus, in many studies, scholars have tried to find strain rate during FSW.As stated before, friction stir welding on stainless steels type 304 and 304L have good recrystallized grain in stir zone. 


\section{REFERENCES}

[1] R. Singh, "Stainless steels," Applied Welding Eng ineering, Chapter 8, pp. $65-73,2012$.

[2] W. M. Thomas, "Friction stir butt welding," International Patent Appl. No. PCT/GB92/02203 and GB Patent Appl. No. 9125978.8, US Patent no. $5460,317,1991$.

[3] M. Russell, "Friction stir welding at TWI," Cambridge: TWI. 2010.

[4] J. Qian, J. Li, F. Sun, J. Xiong, F. Zhang, and X. Lin, “An analytical model to optimize rotation speed and travel speed of friction stir welding for defect-free joint," Scripta Materialia, 2012.

[5] A. P. Reynolds, W. Tang, T. G. Herold, and H. Prask, "Structure, properties, and residual stress of 304L stainless steel friction stir welds," Scripta Materialia, vol. 48, no. 9, pp. 1289-1294, 2003.

[6] H. Cho, H. N. Han, S. Hong, J. Park, Y. Kwon, S. Kim, and R. J. Steel, "Microstructural analysis of friction stir welded ferritic stainless steel," Materials Science and Engineering: A, vol. 528, no. 6, pp. 2889-2894, 2011.

[7] K. V. Jata, and S. L Semiatin, "Continuous dynamic recrystallization during friction stir welding of high strength aluminum alloys," Scripta Materialia, vol. 43, no. 8, pp. 743-749, 2000.

[8] B. Heinz and B. Skrotzki, "Characterization of a friction-stir-welded aluminum alloy 6013," Metallurgical and Materials Transactions B, vol. 33, no. 3, 2002, pp. 489-498.

[9] Y. S. Sato, T. W. Nelson, and C. J. Sterling, "Recrystallization in type 304L stainless steel during friction stirring," ActaMaterialia, vol. 53, no. 3, pp. 637-645, 2005.

[10] S. H. C. Park, Y. S. Sato, H. Kokawa, K. Okamoto, S. Hirano, and M. Inagaki, "Rapid formation of the sigma phase in 304 stainless steel during friction stir welding," ScriptaMaterialia, vol. 49, no. 12, pp. 1175-1180, 2003.

[11] T. Saeid, A. A. zadeh, H. Assadi, and F. MalekGhaini, "Effect of friction stir welding speed on the microstructure and mechanical properties of a duplex stainless steel," Materials Science and Engineering: A, vol. 496, no. 1-2, pp. 262-268, 2008.

[12] H. Schmidt, J. Hattel, and J. Wert, "An analytical model for the heat generation in friction stir welding," Model. Simul. Mater. Sci. Eng., vol. 12, pp. 143-157, 2004.

[13] M. Assidi, L. Fourment, S. Guerdoux, and T. Nelson, "Friction model for friction stir welding process simulation: Calibrations from welding experiments," International Journal of Machine Tools and Manufacture, vol. 50, no. 2, pp. 143-155, 2010.

[14] H. B. Schmidt, and J. H. Hattel, "Thermal modeling of friction stir welding," ScriptaMaterialia, vol. 58, no. 5, pp. 332-337, 2008.

[15] W. S. Lee, J. I. Cheng, and C. F. Lin, "Deformation and failure response of 304L stainless steel SMAW joint under dynamic shear loading," Mater Sc.Eng. A, vol. 381, no. 1-2, pp. 206-15, 2004.

[16] S. H. C. Park, Y. S. Sato, H. Kokawa, K. Okamoto, S. Hirano, and M. Inagaki, SciTechnol Weld Joi.

[17] R. Nandan, T. DebRoy, and H. K. D. H. Bhadeshia, "Recent advances in friction-stir welding-process, weldment structure and properties," Progress in Materials Science, vol. 53, no. 6, pp. 980-1023, 2008.

[18] R. S. Mishra and Z. Y. Ma, "Friction stir welding and processing," Materials Science and Engineering: R: Reports, vol. 50, no. 1-2, pp. $1-78,2005$.

[19] H. Bisadi, A. Tavakoli, M. T. Sangsaraki, and K. T. Sangsaraki, "The influences of rotational and welding speeds on microstructures and mechanical properties of friction stir welded Al5083 and commercially pure copper sheets lap joints," Materials and Design, vol. 43, pp. 80-88, 2013.

[20] M. Ghosh, K. Kumar, and R. S. Mishra, "Friction stir lap welded advanced high strength steels: Microstructure and mechanical properties," Materials Science and Engineering: A, vol. 528, no. 28, pp. 8111-8119, 2011.
[21] J. Qian, J. Li, F. Sun, J. Xiong, F. Zhang, and X. Lin, "An analytical model to optimize rotation speed and travel speed of friction stir welding for defect-free joint," ScriptaMaterialia, vol. 68, issues 3-4, pp. 175-178, 2012.

[22] M. Awang, V. H. Mucino, Z. Feng, and S. A. David, "Thermo-mechanical modeling of friction stir spot welding (FSSW) process: Use of an explicit adaptive meshing scheme," SAE Inter. Paper, vol. 1, pp. 1251-1256, 2005.

[23] T. Saeid, A. A. Zadeh, H. Assadi, and F. MalekGhaini, "Effect of friction stir welding speed on the microstructure and mechanical properties of a duplex stainless steel," Materials Science and Engineering: A, vol. 496, no. 1-2, pp. 262-268, 2008.

[24] T. J. Lienert, W. Stellwag, and L. R. Lehman. Comparison of heat inputs: Friction stir welding vs. arc welding. [Online]. Available: http://174.122.108.74/conferences/abstracts/2002/011.pdf

[25] Ø. Frigaard, Ø. Grong, and O. T. Midling, "A process model for friction stir welding of age hardening aluminum alloys," Metallurgical and materials transactions A, vol. 32, no. 5, pp. 1189-1200, 2001.

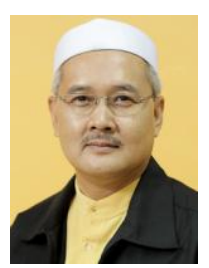

S. Sulaiman was born in Jan 4, 1963. He is a professor in the Department of Mechanical and Manufacturing Engineering, Universiti Putra Malaysia. His major field is Manufacturing Engineering especially in Metal Forming includes simulation/modeling and experimental works. He managed to supervise more than 20 Ph.D. students and published more than 200 International journal and conference papers. He received many recognitions from various organizations, national and international level. Currently he concentrates on processing of new materials include metal and nonmetal composite products.

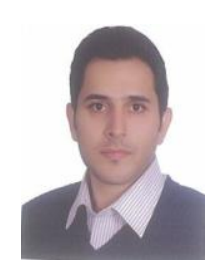

Seyed Sattar Emamian was born in Dec. 16, 1981. He graduated in Master of Manufacturing Systems Engineering from Universiti Putra Malaysia (UPM) in 2013. He was the Managing Diroctor (December, 2009 Augest, 2011) in Mobin Engineering and Trading Co., Tehran, Iran and the other work experiments are as follows: Technical Consultant (2009-2010) in Ertegha Gostar Pouya Co. Quality Control Manager(2005-2009) in Mehrkian Iranian Co. Welding and Non-Destructive Tests Inspector (2003-2005) in Mehrkian Iranian Co. Welding Inspector (2002-2003) inTaghtiran Machinery Co.

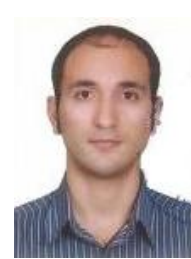

Mohammad Nassir Sheikholeslam was born in Dec. 14, 1982. He is a graduate student in Master of Industrial Engineering in Umiversiti Putra Malaysia. He was the Project Planning Engineer (Senior Executive) (Aug-2011) in Moshanir Power Engineering Consultants, Esfahan, Iran. Other work experiences are as follows: Project Planning Engineer (Senior Executive) in Asgon in Arian Hamro Co. Felez Co. Project Planning Engineer (Senior Executive)

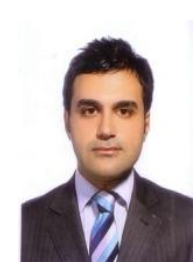

Mehrshad Mehrpouya was born in Sep. 17, 1986. He is a graduate student in Master of Manufacturing Systems Engineering in Universiti Putra Malaysia. His work experiences are as follows: Technical Engineer (2011) in Farsam Co., Tehran, Iran. Technical engineer (2011) in $\mathrm{fm}$ tech co. Technical engineer (2010) in iran khodro. Consultant engineer (2009) in Arian Spadana Co. He managed to attend 9 international conferences. 